Elsevier Editorial System(tm) for Polymer Manuscript Draft

Manuscript Number: POLYMER-15-675R1

Title: Full silicone interpenetrating bi-networks with different organic groups attached to the silicon atoms

Article Type: Research Paper

Section/Category: Physical Chemistry of Polymers

Keywords: interpenetrated networks; dielectric permittivity; mechanical characteristics

Corresponding Author: Dr. Maria Cazacu, Ph.D.

Corresponding Author's Institution: "Petru Poni" Institute of

Macromolecular Chemistry

First Author: Codrin Tugui

Order of Authors: Codrin Tugui; Maria Cazacu, Ph.D.; Liviu Sacarescu; Adrian Bele; George Stiubianu; Cristian Ursu; Carmen Racles

Abstract: Mixed silicone interpenetrating networks have been prepared using two groups of siloxane polymers and copolymers as precursors in different combinations. Each combination chosen, after a good mixing in solution with cross-linking agents was processed into film, which has been stabilized through sequential crosslinking using separate chemical pathways: condensation with tetraethyl orthosilicate at room temperature for the first network and addition (hydrosilylation) at higher temperatures in the case of the second one. The morphology of the resulted materials was studied by scanning electron microscopy (SEM). The mixing degrees of the two networks were estimated on the basis of the differential scanning calorimetry (DSC) traces as well as by small angle X-ray scattering (SAXS). The obtained films were characterized from point of view of the properties of interest for electromechanical applications by mechanical testing, dielectric spectroscopy and electrical breakdown measurements. The influence of the nature and content of the polar groups attached on the silicon on these characteristics was discussed. 


\title{
Full silicone interpenetrating bi-networks with different organic groups attached to the silicon atoms
}

\author{
Codrin Tugui, Maria Cazacu, ${ }^{\star}$ Liviu Sacarescu, Adrian Bele, George Stiubianu, Cristian \\ Ursu, Carmen Racles
}

"Petru Poni" Institute of Macromolecular Chemistry lasi, Aleea Grigore Ghica Voda 41A, 700487, Romania

*Correspondence to: Maria Cazacu (E-mail: mcazacu@icmpp.ro)

\begin{abstract}
Mixed silicone interpenetrating networks have been prepared using two groups of siloxane polymers and copolymers as precursors in different combinations. Each combination chosen, after a good mixing in solution with cross-linking agents was processed into film, which has been stabilized through sequential crosslinking using separate chemical pathways: condensation with tetraethyl orthosilicate at room temperature for the first network and addition (hydrosilylation) at higher temperatures in the case of the second one. The morphology of the resulted materials was studied by scanning electron microscopy (SEM). The mixing degrees of the two networks were estimated on the basis of the differential scanning calorimetry (DSC) traces as well as by small angle X-ray scattering (SAXS). The obtained films were characterized from point of view of the properties of interest for electromechanical applications by mechanical testing, dielectric spectroscopy and electrical breakdown measurements. The influence of the nature and content of the polar groups attached on the silicon on these characteristics was discussed.
\end{abstract}

KEYWORDS: silicones; interpenetrated networks; dielectric permittivity; mechanical characteristics

\section{INTRODUCTION}

Since they have been discovered, the dielectric elastomers (DE's), show a continuous interest due to the wide field of applications including their use as actuators in biomedical engineering, artificial muscles, haptic screens or for energy harvesting. ${ }^{1,2}$ Besides acrylic elastomers, silicones occupy a top position in this research area due to their special properties derived from unique characteristics of the siloxane bond: shortness and large 
angle, accounted either to $(p \rightarrow d) \pi$ back-bonding or to ionic character. ${ }^{3}$ These lead to high intramolecular bond energy and flexible polymer chain. The presence of the organic nonpolar groups attached to the silicon atoms, as in PDMS for example, is the reason for weak intermolecular forces. ${ }^{4}$ Silicones show a unique flexibility, with shear modulus $G$ values between $100 \mathrm{kPa}$ and $3 \mathrm{MPa}$ and loss tangent values, $\tan \sigma<<0.001$. ${ }^{5-7}$ On the other hand, the tensile strength is higher than for most organic elastomers at elevated temperatures. In addition, silicone elastomers can operate in a wide range of temperature, without being affected by the moisture, are resistant to oxygen, ozone and sunlight irradiation, have a good dielectric strength and no toxicity, which make them suitable for a large number of applications. ${ }^{7-11}$ However, as concerning the electromechanical applications, silicones have the disadvantage of a low dielectric permittivity. Therefore, a significant research effort was focused to improve the dielectric permittivity by incorporating various fillers in the polymer matrix or by attaching polar groups to the polymer network. ${ }^{12-26}$ However, by these approaches, the mechanical properties of these materials could be damaged. ${ }^{27}$ As for most electroelastomers, mechanical prestrain is generally required to obtain high electromechanical strain and high elastic energy density although the prestrain causes a reduction in certain parameters of the actuators. An interesting approach is to create and maintain prestrain by interpenetrating polymer networks (IPNs). ${ }^{28}$ In the literature there are a number of polysiloxane-organic polymers interpenetrated networks, those reported before 2000 and excellently reviewed in ref. $^{29}$ It is highlighted the difficulty of obtaining homogeneous networks due to well-known incompatibility of the silicones with almost any organic component. These silicone-containing networks generally have been found useful as pervaporation membrane; in gears, for medical aims (silicone rubber-nylon or PU with trade name Rimplast), in drug release (poly(vinyl alcohol) - polydimethylsiloxane hydrogels), for high temperature damping (polydimethylsiloxane - polyacrylates - polymethacrylates), or sound and vibration damping (polysiloxanes - poly(methyl methacrylate)). ${ }^{30-34}$ The use of interpenetrating polymer networks (IPN) as dielectric elastomers is a less addressed attempt to improve both dielectric and mechanical properties. ${ }^{35,36}$ Only recently the electroactive interpenetrating networks that to deform easily under the influence of an electric field become of interest. In general, these are constructed by generating a network in the presence of a basic, already formed one. ${ }^{35}$ For enhanced deformation of actuation, the primary network is prestrained. ${ }^{33}$ As electroactive elastomers, IPNs based on VHB and poly(1,6-hexanediol diacrylate) or trimethylolpropane trimethacrylate (TMPTMA) as well as IPNs of silicone and $3 \mathrm{M}$ VHB 4910 have been prepared. ${ }^{35-37}$ The interpenetrating polymer networks are formed in the highly prestrained VHB acrylic elastomer network. ${ }^{36}$

Brochu et al. used a commercial kit consisting in soft room temperature vulcanizing (RTV) silicone as the host elastomer and a more rigid high temperature vulcanizing (HTV) silicone 
to prepare IPN. Prestrain was applied to the crosslinked RTV silicone host material, after that the HTV silicone was cured locking the host material in this state..$^{38-40}$

Prompted by the Brochu works, our approach consists in the preparation of siloxane-siloxane networks on the basis of several available, in house prepared polymers as network precursors. ${ }^{38}$ The two networks differ by the nature of the substituents at the silicon atom, by the molecular masses of the precursors and also by the crosslinking path. Polar groups (phenyl, trifluoropropyl, 3-cyanopropyl) were attached to the silicon belonging to one of the network in order to increase the dielectric permittivity. In this case, a big challenge is to find a good compatibility between networks, mainly when one network is more polar then the other, because a phase separation may occur. Further, the interpenetration of two networks with high value of dipole moment can lead to a significant decrease of the breakdown strength. The samples were processed as thin films, which have been stabilized through sequential cross-linking using two separate chemical pathways, without prestrain: one is condensation of $\mathrm{OH}$-terminated siloxane copolymers containing various percents of polar groups (phenyl or trifluoropropyl) along the chain and cured by condensation (used as main network) and, the second one is addition of $\alpha, \omega$-bis(vinyl)polydimethylsiloxane to $\alpha, \omega$-bis(trimethylsiloxy)poly(dimethylmethyl-H-siloxane) or $\quad \alpha, \omega$-bis(trimethylsiloxy)poly(methylcyanopropylmethylhexyl-methylhydro)siloxanes. The mechanical and dielectric properties, morphology and thermal behaviour of the resulting IPNs were studied.

\section{EXPERIMENTAL}

\section{Materials}

$\alpha, \omega$-Bis(trimethylsiloxy)poly(methyl-H-siloxane), $\quad \mathrm{M}_{\mathrm{w}}=2200 \quad \mathrm{~g} \quad \mathrm{~mol}^{-1}$, octaphenyltetracyclosiloxane $\left(D_{4}{ }^{P h}\right), \geq 98 \%$, n-hexene, octamethylcyclotetrasiloxane $\left(D_{4}\right)$, dibutyltin dilaurate (DBTL), 95\%, and hexachloroplatinic(IV) acid hydrate, $\geq 99.9 \%$ trace metals basis, Sigma-Aldrich, Germany, were used as received. 1,3,5-Trimethyl-1,3,5tris(3,3,3-trifluoropropyl)cyclotrisiloxane, 97\%, tetraethylorthosilicate (TEOS), 99.9\%, supplied by Alfa Aesar, Germany were used as such.

Polydimethylsiloxane- $\alpha, \omega$-diol (PDMS) with $M_{n}=377300 \mathrm{~g} \mathrm{~mol}^{-1}$, as determinated by gel permeation chromatography (GPC), was prepared by cationic ring-opening polymerization of octamethylcyclotetrasiloxane $\left(D_{4}\right)$ catalysed by sulphuric acid, according to an already reported procedure. ${ }^{39}$ Polydimethyldiphenylsiloxane- $\alpha, \omega$-diol, PDMDPhS, with $M_{n}=104500 \mathrm{~g}$ $\mathrm{mol}^{-1}$ was prepared by bulk anionic ring opening copolymerization of the octamethylcyclotetrasiloxane $\left(\mathrm{D}_{4}\right)$ and octaphenylcyclotetrasiloxane $\left(\mathrm{Ph}_{4}\right)$, using tetramethylammonium hydroxide as catalyst and a Lewis base (DMF) as promoter, according 
to procedure described in ref. ${ }^{40}$ The content in phenyl groups estimated on the basis of ${ }^{1} \mathrm{H}$ NMR was $18.4 \mathrm{~mol} \%$ (Figure 1).

Polydimethylmethyl-3,3,3-trifluoropropylsiloxane- $\alpha, \omega$-diol, PDMTFS, $M n=64800 \mathrm{~g} \mathrm{~mol}^{-1}$, was prepared by ring-opening copolymerization of $D_{4}$ with 1,3,5-trimethyl-1,3,5-tris(3,3,3trifluoropropyl)cyclotrisiloxane in the presence of cation-exchanger, Purolite CT-175. The content of trifluoropropyl groups estimated from ${ }^{1} \mathrm{H}$ NMR spectrum was 15.4 mol\% (Figure 1). The $\alpha, \omega$-bis(trimethylsiloxy)poly(dimethylmethyl-H-siloxane), PDMMHS, was synthetized by equilibrium copolymerisation of $\mathrm{D}_{4}$ with $\alpha, \omega$-bis(trimethylsiloxy)poly(methyl-H-siloxane) homopolymer in the presence of Purolite CT-175. ${ }^{39}$ The molecular mass of the resulted copolymer determined by GPC was $M_{n}=17800 \mathrm{~g} \mathrm{~mol}^{-1}$. Based on ${ }^{1} \mathrm{H}$ NMR spectrum it has been estimated a content of $19.2 \mathrm{~mol} \% \mathrm{Si}-\mathrm{H}$ groups (Figure 1). This copolymer was used as a precursor to generate Net B, or in general the second networks, by hydrosilylation with another one containing vinyl group (see below $\mathrm{Vi}_{2}$ PDMS). The $\alpha, \omega$ bis(trimethylsiloxy)poly(methylcyanopropyl-methylhexyl-methylhydro)siloxanes, PMCyMHS and $\mathrm{PMCyMHS}_{2}$, with 3-cyanopropyl/hexyl/hydro contents 9.2/82.9/8.9 and 62.1/26.9/11 and $M n=4600$ and 4200 , respectively were prepared by co-hydrosilylation reactions of the commercial $\alpha, \omega$-bis(trimethylsiloxy)poly(methyl-H-siloxane) with found molecular weight $\mathrm{Mn}$ of $2200 \mathrm{~g} \mathrm{~mol}^{-1}$, with allylcyanide and $\mathrm{n}$-hexene. ${ }^{24} \alpha, \omega$-Bis(vinyl)polydimethylsiloxane, $\mathrm{Vi}_{2}$ PDMS, was synthesized by an equilibrium cationic ring-opening polymerisation of $D_{4}$ in presence of 1,3-bis(vinyl)tetramethyldisiloxane used to block the chains ends. ${ }^{41}$ The resulted polymer had $M_{n}=40200 \mathrm{~g} \mathrm{~mol}^{-1}$ as determined by GPC and was used in the addition reaction to achieving the second network of IPN. The percentages of the polar units contained in copolymers were calculated from ${ }^{1} \mathrm{H}$ NMR spectra (Figure 1). 


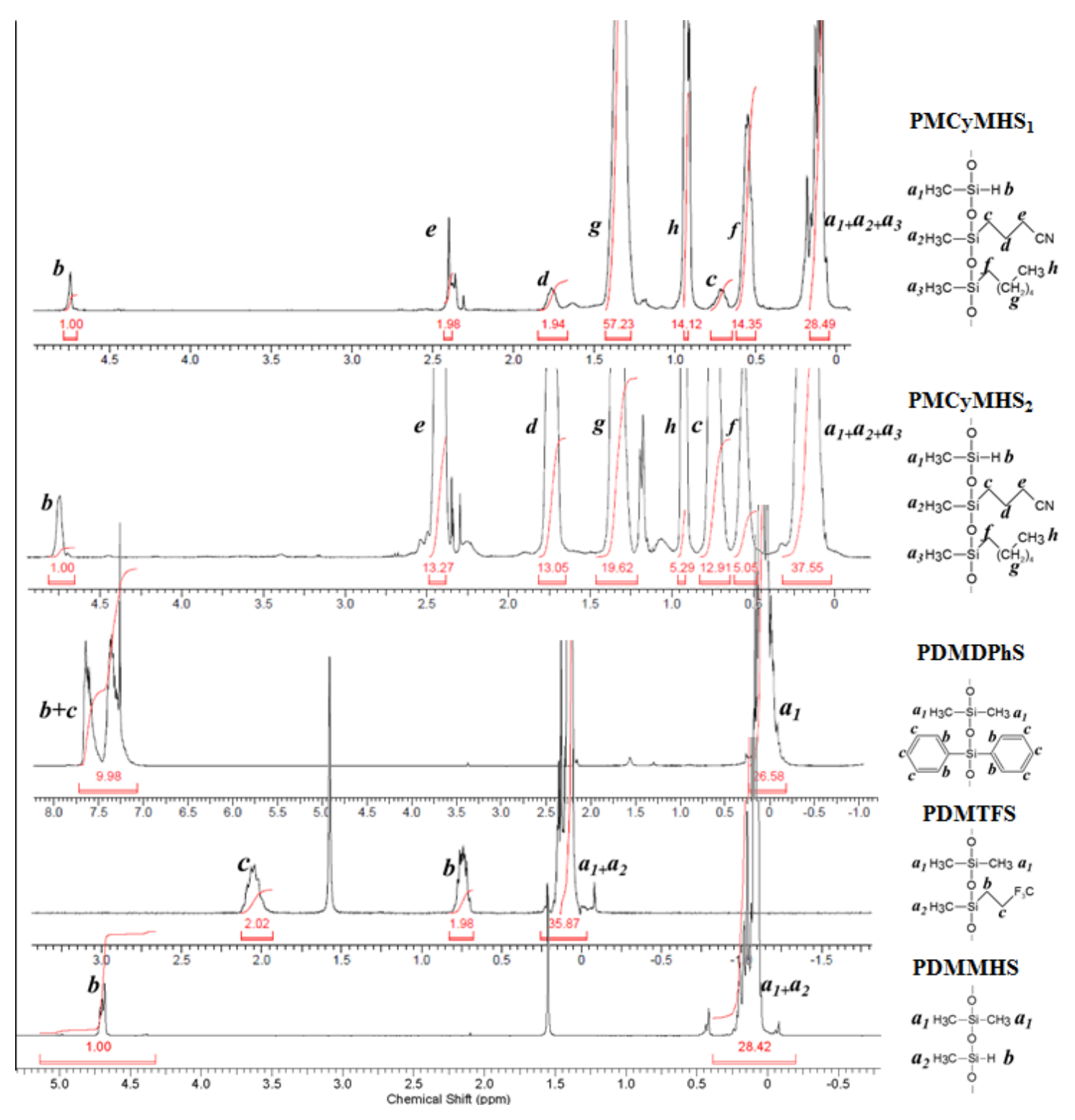

FIGURE 1 NMR spectra of precursors for IPNs having different substituents to the silicon atoms: PDMMHS - bis(trimethylsiloxy)poly(dimethylmethylmethyl-H-siloxane); PDMTFS polydimethylmethyl-3,3,3-trifluoropropylsiloxane- $\alpha, \omega$-diol; PDMDPhS polydimethyldiphenylsiloxane- $\alpha, \omega$-diol; $\mathrm{PMCyMHS}_{1}$ and $\mathrm{PMCyMHS}_{2} \quad-\alpha, \omega$ bis(trimethylsiloxy)poly(methylcyanopropyl-methylhexyl-methylhydro)siloxanes.

\section{Equipments}

The Fourier transform infrared (FTIR) spectra were recorded in $\mathrm{KBr}$ pellets and ATR mode with Bruker Vertex 70 FTIR instrument, at room temperature. ${ }^{1} \mathrm{H}$ NMR spectra were recorded on a Bruker Advance III $400 \mathrm{MHz}$ spectrometer, using $\mathrm{CDCl}_{3}$ as solvent. The molecular mass of the polymers was determined by gel permeation chromatography (GPC) in $\mathrm{CHCl}_{3}$ on a PL-EMD 950 chromatograph/evaporative mass detector instrument. The morphology of the films was studied by scanning electron microscope (ESEM) type Quanta 200 operating at 20kV with 
secondary and backscattering electrons in low vacuum mode. DSC measurements were performed with a DSC 200 F3 Maia (Netzsch, Germany). About 10mg of sample was heated in pressed and punched aluminium crucibles at a heating rate of $10^{\circ} \mathrm{C} \mathrm{min}^{-1}$. Nitrogen was used as inert atmosphere at a flow rate of $100 \mathrm{~mL} \mathrm{~min}^{-1}$. Small angle X-ray scattering (SAXS) measurements were carried out using a Bruker NanostarU instrument equipped with a X-ray $\mathrm{I} \mu \mathrm{S}$ microsource with copper anode and a three-pinhole collimation system. A high sensitive 2D detector, Vantec-2000, having $68 \mu \mathrm{m}$ resolution was used to record the scattered intensity. The scattered intensity $\mathrm{I}(\mathrm{q})$ is measured as a function of the momentum transfer vector $q=4 \pi \sin \theta / \lambda$, where $\lambda$ is the wavelength of the $X$-rays (Cu Ka radiation, $1.54 \AA$ ), and $\theta$ is half the scattering angle. The sample-to-detector distance was $107 \mathrm{~cm}$ allowing measurements with $q$ values between $0.008 \AA^{-1}$ and $0.3 \AA^{-1}$. The angular scale was calibrated by the scattering peaks of a silver behenate standard. The samples to be analyzed have been prepared by cutting small square pieces of about $5 \times 5 \mathrm{~mm}$ of thin IPN films, 0.5 $\mathrm{mm}$ thick. Then, they were mounted in the dedicated holder and placed inside the sample chamber of the instrument. The IPN samples have been maintained at $25^{\circ} \mathrm{C}$ and vacuum for $6 \mathrm{~h}$ before starting the measurements. The raw data was normalized for the transmission coefficient and the incoherent scattering due to the background was subtracted in the data analysis using SAXS-NT ${ }^{42}$ software. The collected 2D patterns were further reduced by azimuthal integration to $1 \mathrm{D}$ plots where the intensity of the scattering, I, is printed versus the momentum transfer vector, $\mathrm{q}$.

Mechanical tests were performed on dumbbell-shaped cut samples from thin films on a TIRA test 2161 apparatus, Maschinenbau GmbH Ravenstein, Germany. Measurements were run at an extension rate of $20 \mathrm{~mm} \mathrm{~min}^{-1}$, at ambient temperature. To test the fatigue resistance, five cycles were run with: stationary time at maximum strength $5 \mathrm{~s}$, stationary time at minimum strength $5 \mathrm{~s}$, maximum strain $100 \%$ and minimum strain $2 \%$. The dielectric measurements were done with Novocontrol setup (Broadband dielectric spectrometer Concept 40, GmbH Germany) integrating an ALPHA frequency response analyzer and a Quatro temperature control system, with frequency range $10^{0}-10^{6} \mathrm{~Hz}$, at room temperature. The bias voltage applied across the sample was $1.0 \mathrm{~V}$. The samples with uniform thickness were placed between copper plated round electrodes. Breakdown strength measurements were performed in actuation mode, by applying a ramp signal of $400 \mathrm{~V} \mathrm{~s}^{-1}$ on unstressed elastomeric membranes of $22 \mathrm{~mm}$ diameter placed between two unequal planar circular electrodes arranged coaxially, as described in ref. ${ }^{43}$ The high voltage electrode dimensions were $25 \mathrm{~mm}$ in radius and $25 \mathrm{~mm}$ high. The grounded electrode dimensions were $150 \mathrm{~mm}$ in radius and $5 \mathrm{~mm}$ high. The voltage could vary in the range $0 \div 20 \mathrm{kV}$ until the breakdown occurred. Five measurements were made for each sample and the average value was taken into account. 


\section{Procedure for preparing IPNs}

All networks were prepared according to the general procedure described below. Thus, $2 \mathrm{~g}$ polymer precursor for the first network was dissolved in $20 \mathrm{~mL}$ chloroform, and then different amounts of precursors for the second network ( $\mathrm{Vi}_{2} \mathrm{PDMS}$ and PDMMHS, PMCyMHS ${ }_{1}$ or $\mathrm{PMCyMHS}_{2}$ ) were added according to Table 1. After mixing the precursor polymers, $0.16 \mathrm{ml}$ crosslinker (TEOS) and $0.01 \mathrm{ml}$ catalyst (DBTDL) for the first network were added and stirred together. Then, $0.01 \mathrm{ml}$ Speier's catalyst (hexachloroplatinic(IV) acid, $2 \mathrm{wt} \%$ solution in isopropanol) was added as a catalyst for the formation of the second network by hydrosilylation and were mixed well. The obtained solutions were drop cast on teflon substrate frames and were left for three days to allow the curing of the first network through a condensation reaction and evaporation of the solvent and by-products. After the first crosslinking was complete, the obtained films, of about $200 \mu \mathrm{m}$ thickness, were peeled off from substrate and heated at $180^{\circ} \mathrm{C}$ for 30 minutes allowing curing the second network through a hydrosilylation reaction. Before to be tested, the obtained films were aged in normal conditions for two weeks. 
TABLE 1 Recipes used for preparing the IPNs (for first network: crosslinker - $0.16 \mathrm{ml}$ TEOS; catalyst - $0.01 \mathrm{ml}$ DBTDL; for the second network: catalyst $-0.01 \mathrm{ml}$ hexachloroplatinic acid, $2 \mathrm{wt} \%$ solution in anhydrous isopropanol)

\begin{tabular}{|c|c|c|c|c|c|c|c|c|c|c|c|c|}
\hline \multirow{2}{*}{$\begin{array}{l}\text { IPN } \\
\text { code }\end{array}$} & \multicolumn{4}{|c|}{ Precursors of the first network } & \multicolumn{6}{|c|}{ Precursors of the second network } & \multirow{2}{*}{$\begin{array}{c}\text { Mol\% } \\
\text { polar } \\
\text { groups in } \\
\text { individual } \\
\text { network } \\
\text { precursor }\end{array}$} & \multirow{2}{*}{$\begin{array}{l}\text { Mol\% } \\
\text { polar } \\
\text { groups } \\
\text { in IPN }\end{array}$} \\
\hline & $\mathrm{R}$ & $\mathrm{R}^{\prime}$ & $\mathrm{Mn}$ & $\begin{array}{l}\mathrm{m}, \\
{[\mathrm{g}]}\end{array}$ & $\mathrm{R}_{1}$ & $\mathrm{R}_{2}$ & $\begin{array}{c}\mathrm{Mn} \\
\text { VizPDMS }\end{array}$ & $\begin{array}{c}\mathrm{m} \\
\text { Vi2PDMS, } \\
{[\mathrm{g}]}\end{array}$ & $\begin{array}{l}\mathrm{Mn}_{\text {PDMMHS/ }} \\
\mathrm{Mn}_{\text {PMCYMHS }^{*}}\end{array}$ & $\begin{array}{c}\mathrm{m}_{\mathrm{PDMMHS}} / \\
\mathrm{m}_{\mathrm{PMCYMHS}} \text {, } \\
{[\mathrm{g}]}\end{array}$ & & \\
\hline$\overline{\text { NetA }}$ & $\mathrm{CH}_{3}$ & $\mathrm{CH}_{3}$ & 377300 & 2 & - & - & - & 0 & - & 0 & 0 & 0 \\
\hline NetB & - & - & - & 0 & $\mathrm{CH}_{3}$ & $\mathrm{CH}_{3}$ & 40200 & 2.71 & 17800 & 0.28 & 0 & 0 \\
\hline $\begin{array}{l}\text { IPN- } \\
\mathrm{R}\end{array}$ & $\mathrm{CH}_{3}$ & $\mathrm{CH}_{3}$ & 377300 & 2 & $\mathrm{CH}_{3}$ & $\mathrm{CH}_{3}$ & 40200 & 0.36 & 17800 & 0.04 & 0 & 0 \\
\hline $\begin{array}{l}\text { IPN- } \\
\text { P1 }\end{array}$ & $\mathrm{C}_{6} \mathrm{H}_{5}$ & $\mathrm{C}_{6} \mathrm{H}_{5}$ & 104500 & 2 & $\mathrm{CH}_{3}$ & $\mathrm{CH}_{3}$ & 40200 & 0.73 & 17800 & 0.07 & 18.4 & 12.1 \\
\hline $\begin{array}{l}\text { IPN- } \\
\text { P2 }\end{array}$ & $\mathrm{C}_{6} \mathrm{H}_{5}$ & $\mathrm{C}_{6} \mathrm{H}_{5}$ & 104500 & 2 & $\mathrm{CH}_{3}$ & $\mathrm{CH}_{3}$ & 40200 & 0.36 & 17800 & 0.04 & 18.4 & 14.6 \\
\hline $\begin{array}{l}\text { IPN- } \\
\text { F1 }\end{array}$ & $\mathrm{F}_{3} \mathrm{C}_{3} \mathrm{H}_{4}$ & $\mathrm{CH}_{3}$ & 64800 & 2 & $\mathrm{CH}_{3}$ & $\mathrm{CH}_{3}$ & 40200 & 0.73 & 17800 & 0.07 & 15.4 & 10.5 \\
\hline $\begin{array}{l}\text { IPN- } \\
\text { F2 }\end{array}$ & $\mathrm{F}_{3} \mathrm{C}_{3} \mathrm{H}_{4}$ & $\mathrm{CH}_{3}$ & 64800 & 2 & $\mathrm{CH}_{3}$ & $\mathrm{CH}_{3}$ & 40200 & 0.36 & 17800 & 0.04 & 15.4 & 12.5 \\
\hline $\begin{array}{l}\text { IPN- } \\
\text { CN1 }\end{array}$ & $\mathrm{CH}_{3}$ & $\mathrm{CH}_{3}$ & 373000 & 2 & $\begin{array}{c}\mathrm{C}_{3} \mathrm{H}_{4-}^{-} \\
\mathrm{CN}\end{array}$ & $\begin{array}{c}\mathrm{n}- \\
\mathrm{C}_{6} \mathrm{H}_{13}\end{array}$ & 40200 & 0.22 & $4600^{\mathrm{a})}$ & $0.15^{\mathrm{a})}$ & $9.2(\mathrm{CN})$ & 0.3 \\
\hline $\begin{array}{l}\text { IPN- } \\
\text { CN2 }\end{array}$ & $\mathrm{CH}_{3}$ & $\mathrm{CH}_{3}$ & 373000 & 2 & $\begin{array}{c}\mathrm{C}_{3} \mathrm{H}_{4^{-}} \\
\mathrm{CN}\end{array}$ & $\begin{array}{c}\mathrm{n}- \\
\mathrm{C}_{6} \mathrm{H}_{13}\end{array}$ & 40200 & 0.26 & $4200^{\text {a) }}$ & $0.15^{\mathrm{a})}$ & $\begin{array}{l}62.1 \\
(\mathrm{CN})\end{array}$ & 2.4 \\
\hline
\end{tabular}

a) This was used as an alternative to PDMMHS in the cases of IPN-CN1 and IPN-CN2

\section{RESULTS AND DISCUSSION}

For the preparation of the siloxane IPNs, we adapted the procedure described in [ref. 38], according to which two polydimethylsiloxane networks differing by the crosslinking pattern are interpenetrated. Different from this approach, in our work one of the two networks contains different amounts of polar groups attached to the silicon atom: phenyl trifluoropropyl or 3-cyanopropyl. Based on the dipole moment values of the organic groups attached to the silicon atom and estimated by using HyperChem(TM) $\left(0.22,1.30,2.85\right.$, and 2.92 for $-\mathrm{CH}_{3}$, $\mathrm{C}_{6} \mathrm{H}_{5}$, $-\left(\mathrm{CH}_{2}\right)_{2}-\mathrm{CF}_{3},-\left(\mathrm{CH}_{2}\right)_{3}-\mathrm{CN}$, respectively), the order of the polarity of these groups is: $\left(\mathrm{CH}_{2}\right)_{3}-\mathrm{CN}>-\left(\mathrm{CH}_{2}\right)_{2}-\mathrm{CF}_{3}>-\mathrm{C}_{6} \mathrm{H}_{5}>-\mathrm{CH}_{3}{ }^{44}$ In principle, we prepared two networks (Figure 2): the first one consisting in polydiorganosiloxane- $\alpha, \omega$-diols of high molecular masses (PDMS $377300 \mathrm{~g} \mathrm{~mol}^{-1}$, PDMTFS - $64800 \mathrm{~g} \mathrm{~mol}^{-1}$ or PDMDPhS - $104500 \mathrm{~g} \mathrm{~mol}^{-1}$ ) crosslinked by condensation at room temperature with TEOS. The second one consists in a mixture of $\alpha, \omega-$ bis(vinyl)polydimethylsiloxane $\left(\mathrm{Vi}_{2} \mathrm{PDMS}\right)$ with molecular mass $\mathrm{M}_{\mathrm{n}}=40200 \mathrm{~g} \mathrm{~mol}^{-1}$ and $\alpha, \omega$ bis(trimethylsiloxy)poly(dimethylmethyl-H-siloxane) (PDMMHS) with $\mathrm{Mn}=17800 \mathrm{~g} \mathrm{~mol}^{-1}$ and a content of $19.2 \mathrm{~mol} \% \mathrm{Si}-\mathrm{H}$ groups or $\alpha, \omega$-bis(trimethylsiloxy)poly(methylcyanopropyl- 
methylhexyl-methylhydro)siloxanes, $\mathrm{PMCyMHS}_{1}$ and $\mathrm{PMCyMHS}_{2}$, with molecular masses of 4200 and 4600 and CN-propyl groups content of 62.1 and $9.2 \mathrm{~mol} \%$, respectively, in quantities to ensure stoichiometric ratio between $\mathrm{Si}-\mathrm{CH}=\mathrm{CH}_{2}$ and $\mathrm{Si}-\mathrm{H}$ groups (Table 1). These were crosslinked by addition in presence of platinum catalyst. The attempt to crosslink this network in the presence of Karstedt's catalyst failed since the reaction takes place instantaneously not allowing processing of the material in good conditions in the films form. In fact, as demonstrated in a previous publication, ${ }^{45}$ a dehydrocoupling reaction between $\mathrm{Si}$ $\mathrm{H}$ and $\mathrm{Si}-\mathrm{OH}$ groups (resulted from partial hydrolysis of $\mathrm{Si}-\mathrm{H}$ in atmosphere) occurs, with formation of SiOSi bond and hydrogen releasing, similar to that proved between $\mathrm{Si}-\mathrm{H}$ and $\mathrm{C}$ $\mathrm{OH}$ with formation of SiOC bond. ${ }^{46}$ Therefore, we chose different conditions which allowed better control of crosslinking, i.e. Speier's catalyst and high temperature. No gas releasing was observed in this case.
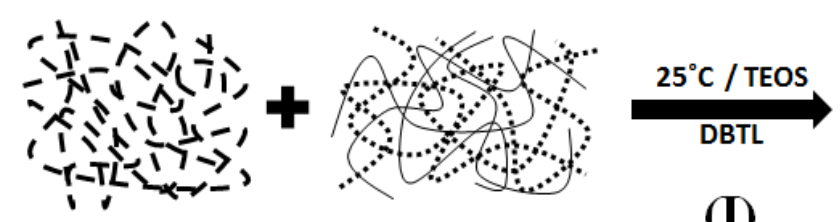

(1)
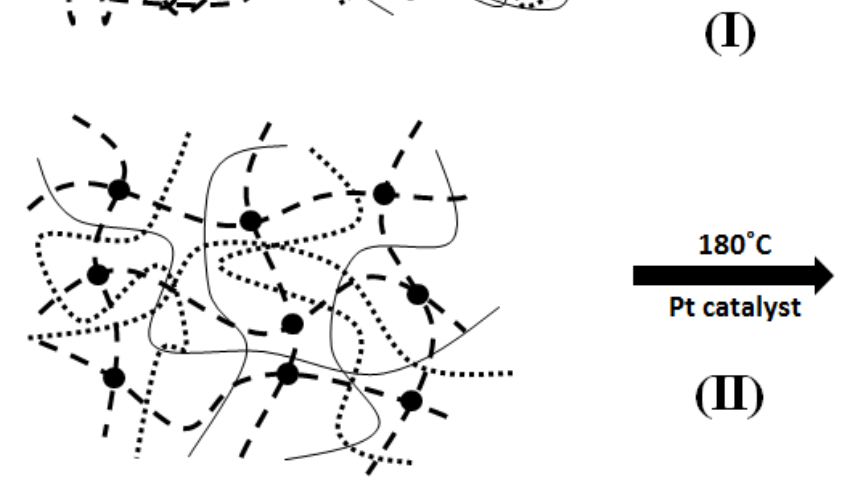

(II)
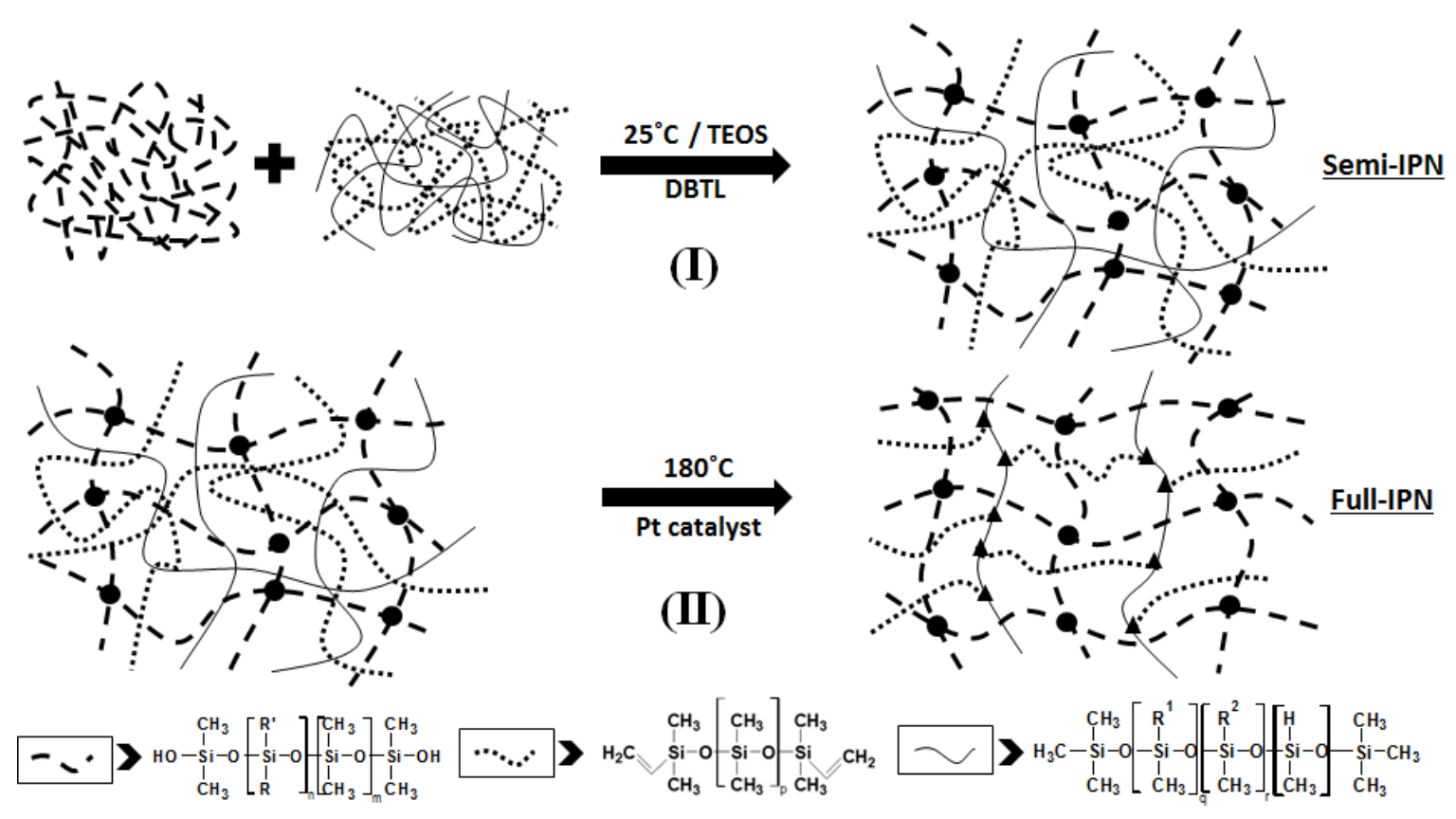

FIGURE 2 The sequential pathway to prepare IPN films: I - the mixing in solution of the IPN precursors and formation of the first network by crosslinking at room temperature, followed by evaporation of the solvent and condensation by-products; II - formation of the second network by hydrosilylation at higher temperature.

To get a clear picture of the effects obtained by interpenetration of the two networks as well as by the presence of the polar groups, three reference samples were prepared consisting in two individual networks based on the polymer precursors without polar groups (blank Net $A$ and Net $B$, respectively) and the derived interpenetrated network (blank IPN-R). The extracts obtained by immersing the samples in THF for 48 hours under stirring are between 14.6-16.5 wt\% (Table 2). 
TABLE 2 The extract obtained after $48 \mathrm{~h}$ immersion in THF

\begin{tabular}{|c|c|c|c|c|}
\hline \multirow{2}{*}{ Sample } & \multirow{2}{*}{$\begin{array}{c}\text { Extract, } \\
\text { [wt\%] }\end{array}$} & \multicolumn{2}{|c|}{$\begin{array}{l}\text { Polar group content, } \mathrm{mol} / 100 \mathrm{~mol} \mathrm{SiO} \text { units } \\
\qquad(\mathrm{mol} / 100 \mathrm{~g} \mathrm{IPN})\end{array}$} & \multirow{2}{*}{$\begin{array}{l}\text { Polar group amount in extract } \\
\text { reported to initial IPN, mol/100 } \\
\text { mol SiO units (mol/100 g IPN) }\end{array}$} \\
\hline & & in initial IPN & in THF extract & \\
\hline Net A & 21.4 & - & - & - \\
\hline Net B & 3.1 & - & - & - \\
\hline IPN-P1 & 16.4 & n.d. & n.d. & n.d. \\
\hline IPN-P2 & 15.8 & n.d. & n.d. & n.d. \\
\hline IPN-F1 & 14.9 & n.d. & n.d. & n.d. \\
\hline IPN-F2 & 14.6 & n.d. & n.d. & n.d. \\
\hline IPN-CN1 & 16.5 & $0.3(0.004)$ & $3.4(0.034)$ & $0.7 \cdot 10^{-3}\left(9.3 \cdot 10^{-6}\right)$ \\
\hline IPN-CN2 & 15.1 & $2.4(0.031)$ & $24.4(0.308)$ & $0.25(0.003)$ \\
\hline
\end{tabular}

n.d. - not determined

Analyzing the extraction behaviour of networks $A$ and $B$, it can be seen that, as expected, network $B$ crosslinked by hydrosilylation with a ladder pattern shows the smallest soluble fraction, while network A consisting of a high molecular weight PDMS (377300) cross-linked by the chain ends as a result of hydrolytic condensation with TEOS shows the highest soluble fraction. Such behaviour of Net $A$ is explicable due to the number of chains in a given mass is small and a single so long uncrosslinked chain that dissolves in the extraction solvent has a high contribution in the extracted masses. In addition, the presence of the macrocycles in high molecular mass PDMS is not excluded. In the case of the IPN-CNs, there may be a suspicion that the involvement of Si-H groups of the copolymer precursors in hydrosilylation reaction would be hampered because of steric hindrance exerted by neighbouring cyanopropyl and hexyl groups and the formation of this network could be compromised. ${ }^{24,47}$ However, the soluble fractions in the two networks are within the limits registered for the other networks. The percentage contents of the $\mathrm{CN}$ groups in these, estimated on the basis of ${ }^{1} \mathrm{H}$ NMR spectra, although about 10 times higher (3.44 and 24.4 mol\% for IPN-CN1 and IPN-CN2 extract, respectively) than in the original samples (0.3 and $2.4 \mathrm{~mol} \%$ for IPN-CN1 and IPN-CN2, respectively), when relate to the initial sample weight submitted to extraction are actually very small $(0.0007$ and $0.2530 \mathrm{~mol} \%)$. The presence of the catalyst (DBTDL) in the extracts is visible both in FTIR (band for ester group at $1732 \mathrm{~cm}^{-}$ ${ }^{1}$ ) and in ${ }^{1} \mathrm{H}$ NMR spectra (peaks at 1.43, 1.26 and 0.84 ppm). Qualitative information about the content of $\mathrm{CN}$ and $\mathrm{Si}-\mathrm{H}$ groups could also be obtained on the basis of FTIR spectra (Figure 1S), considering the band at $1263 \mathrm{~cm}^{-1}$ assigned to $\mathrm{Si}-\mathrm{CH}_{3}$ bond as reference band (Table 3). Considering that one of the networks is mainly composed of chains containing dimethylsiloxane units and the other contains more polar $(\mathrm{CN})$ or less polar (trifluoropropyl, phenyl) groups in different ratios, depending on their nature and distribution pattern along the 
chain or network, phase separation is possible to occur that could affect both mechanical and dielectric properties. ${ }^{48}$

TABLE 3 The intensity ratios of the representative IR absorption bands for the sample IPNCN2 as such, extracted in THF for $48 \mathrm{~h}$, as well as for dried extract fraction

\begin{tabular}{lcc}
\hline Sample & $\mathrm{A}_{\mathrm{CN}} / \mathrm{A}_{1263}{ }^{\mathrm{a}}$ & $\mathrm{A}_{\mathrm{Si}-\mathrm{H}} / \mathrm{A}_{1263}{ }^{\mathrm{b}}$ \\
\hline initial & 0.065 & 0.070 \\
extracted & 0.047 & 0.021 \\
extract & 0.293 & 0.084
\end{tabular}

\footnotetext{
${ }^{\text {a) }} \mathrm{A}_{\mathrm{CN}}, \mathrm{A}_{1263}$ - absorbance intensity for $\mathrm{C} \equiv \mathrm{N}\left(2147 \mathrm{~cm}^{-1}\right)$ and $\mathrm{Si}-\mathrm{CH}_{3}\left(1263 \mathrm{~cm}^{-1}\right)$ bond, respectively; ${ }^{\text {b) }} \mathrm{A}_{\mathrm{Si}-\mathrm{H}}$ - absorbance intensity for $\mathrm{Si}-\mathrm{H}$ bond $\left(2170 \mathrm{~cm}^{-1}\right)$
}

SEM analysis of the cryofractured films reveals a homogeneous structure in the case of blank IPN-R (Figure 3a), while the images of IPNs having polar groups attached to the silicon atoms, even in lowest content, indicate biphasic morphology of the materials (Figure 3b,c,d).
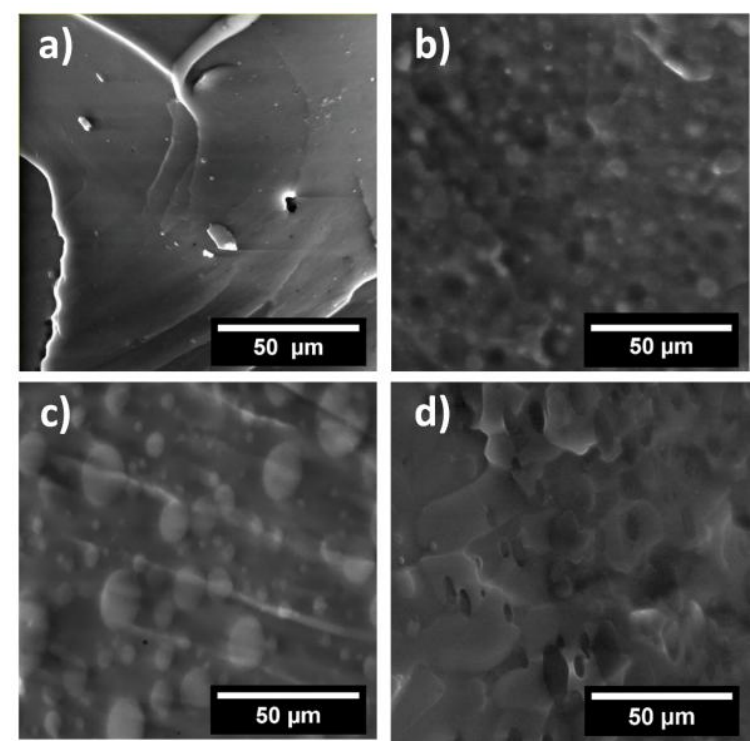

FIGURE 3 SEM images of cryo-fractured films: a) IPN-R, b) IPN-P1, c) IPN-F1 and d) IPNCN2.

To further investigate the phase separation, DSC curves were registered and are presented in Figure 4. Practically, the glass transition temperature and enthalpy depend on the level of cross-linking, which is affected by the degree of mixing and/or the level of interpenetrating polymer chains. In a phase-separated system, several glass transition temperatures may be registered corresponding to each component. In a homogeneous system, there is a single 
glass transition, generally ranging between transitions of the components that make up the system. ${ }^{49}$ The DSC scans (Figure 4) revealed for IPN-R, as expected, a single Tg around $123{ }^{\circ} \mathrm{C}$. IPN-P1 also exhibited a single glass transition at $-87^{\circ} \mathrm{C}$ as a result of the good mixing (presumed by interpenetration) of PDMS with more rigid dimethyldiphenylsiloxane random copolymeric chain.
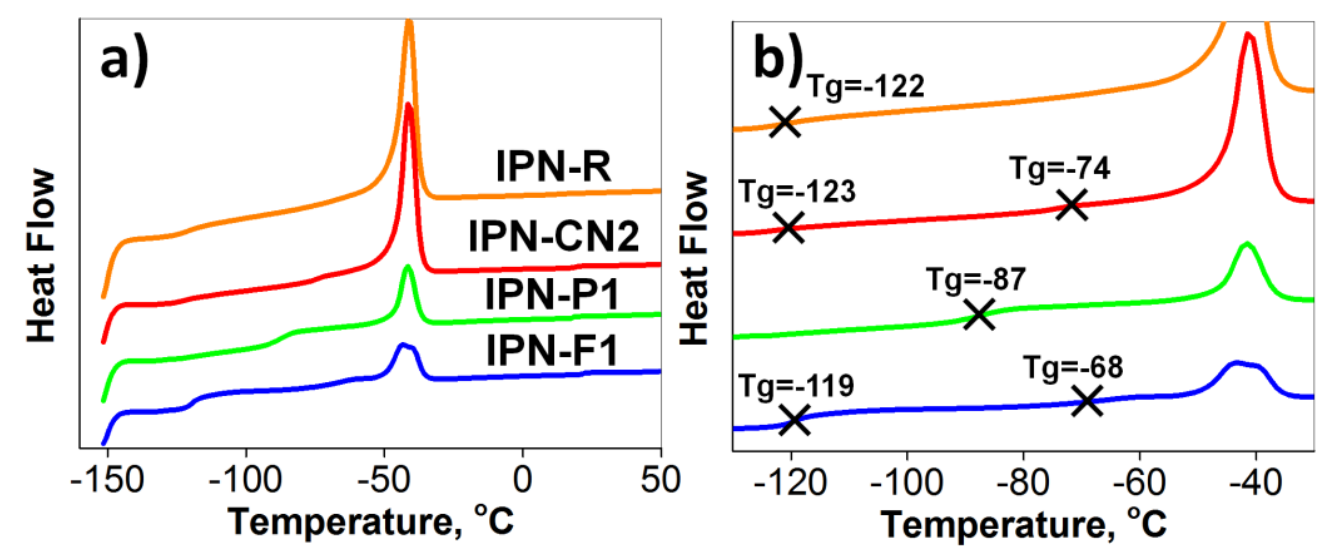

FIGURE 4 DSC traces for samples IPN-R, IPN-P1, IPN-F1, IPN-CN2: a) - on the entire temperature range analyzed; b) - details emphasizing glass transitions within negative temperature range.

The samples IPN-F1 and IPN-CN2 show two glass transition pairs, at -119 and $-68{ }^{\circ} \mathrm{C}$, and at -124 and $-75^{\circ} \mathrm{C}$, respectively, clearly indicating a phase separations, as SEM images also showed. All samples exhibited an endothermal peak at around $-40^{\circ} \mathrm{C}$ assigned to melting of PDMS. ${ }^{50}$ These peaks are not identical in the four types of IPNs, their intensities indicating different crystallization propensity during the cooling of the samples (Table 1S). For example, IPN-F1 exhibited a polymorphic melting, while IPN-CN2 showed a very pronounced melting endotherm, in agreement with the most pronounced phase separation, as a consequence of the largest difference in polarity between the two components.

The IPN films in which there are premises for phase separation, as SEM and DSC analyses already emphasized, were analysed by SAXS. Figure 5 shows the obtained SAXS curves (plots of the scattered intensity (I) versus the scattering vector (q) in logarithmic form) for IPN-F2 and IPN-CN2. The samples have the characteristics of typical non-crystalline polymer mixtures. The morphological aspects of the studied IPNs can be revealed by means of the Debye-Bueche method. ${ }^{51-53}$ 

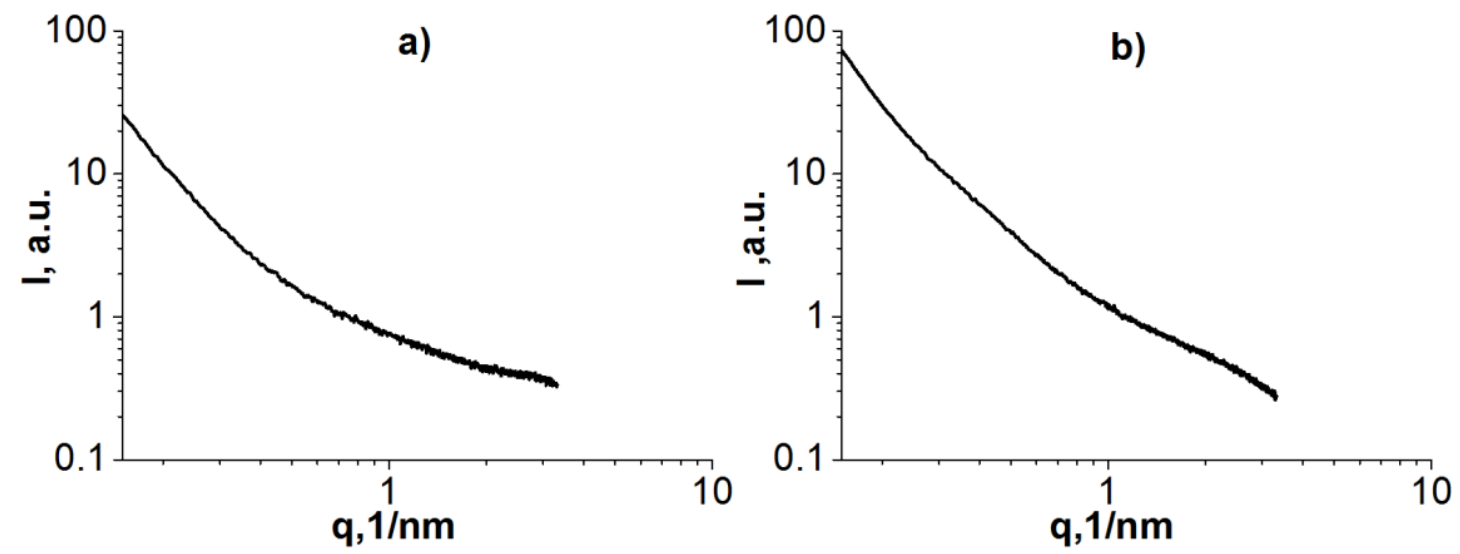

FIGURE 5 SAXS curves for the IPNs having the highest percents of most polar groups: a) IPN-F2; b) IPN-CN2.

This approach is based on the correlation function theory. The correlation function, $g(r)$, can be obtained by the Fourier transformation of the scattering intensity, I(q). For undefined morphological domains separated at distance $r$, the correlation function, $g(r)$, is given by the equation (1): ${ }^{54}$

$$
g(r)=e^{\left(-\frac{r}{a_{e}}\right)}
$$

The coefficient $a_{c}$ represents the correlation distance defined as the size of an inhomogeneity existent in the sample (Figure 6).

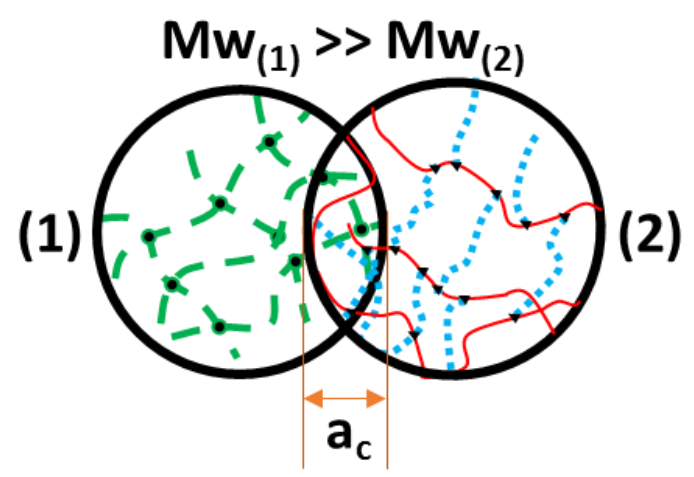

FIGURE 6 Schematic representation of the morphological domains and their parameters: (1) - the first network; (2) - the second network; $a_{c}$ - short range correlation length.

Since the corresponding scattering intensity could be defined as:

$$
\frac{1}{I(q)}=\left[\frac{1}{A}+\left(\frac{a_{c}^{2}}{A}\right) \times q^{2}\right]^{2}
$$


where $A$ is a constant, then, $a_{c}$ is easily calculated by plotting $I(q)^{-1 / 2}$ versus $q^{2}$, a graphical approach (Figure 7) which is known as Debye-Bueche plot: ${ }^{55}$

$$
a_{c}=\frac{\left(\frac{\text { slope }}{\text { intercept }}\right)^{2}}{2 \pi}
$$
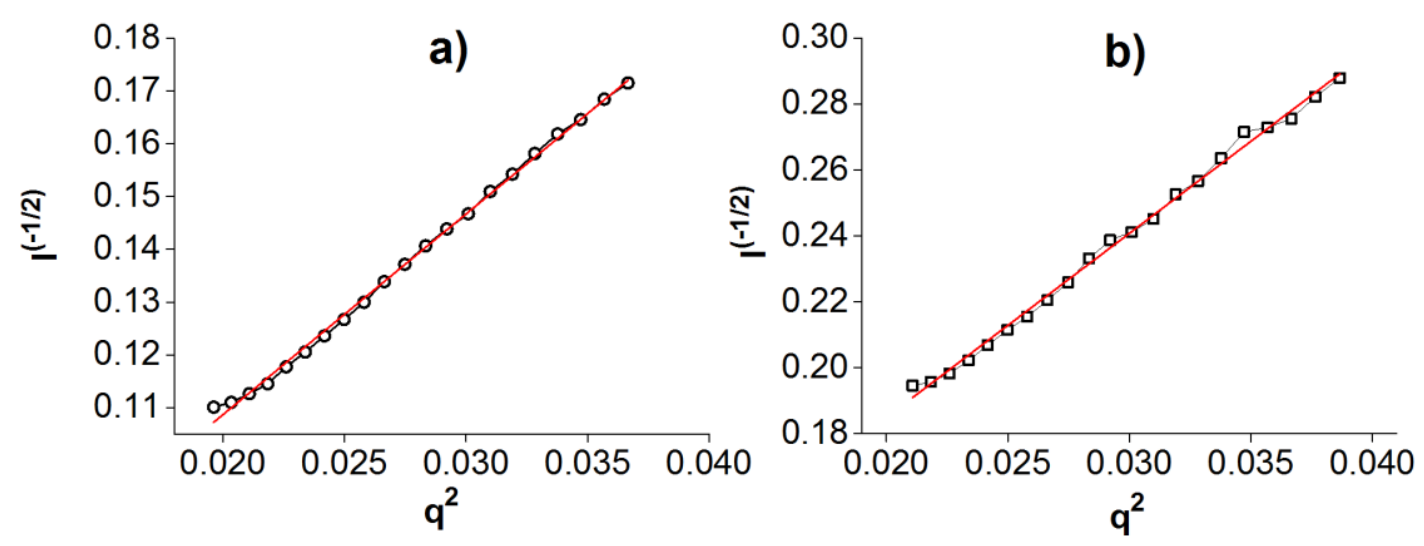

FIGURE 7 Linear part of the Debye-Bueche plot for the studied IPNs: a) IPN-F2; b) IPN-CN2.

The linear part of these plots was used to obtain the short range correlation length, $a_{c}$; it has been found 1.71 and $1.39 \mathrm{~nm}$ for IPN-F2 and IPN-CN2, respectively. It is accepted that the Debye theory provides a general description of an inhomogeneous system, from which scattering measurements can be used to indicate average electron density and the degree of correlation between two fluctuations as a function of their distance of separation. The calculated correlation lengths show that the size of inhomogeneity is higher in IPN-F2 compared with IPN-CN2. The values are small which suggests that the phase separation and scattered intensity are reduced probably because of the internetwork grafting. ${ }^{56,57}$ Such IPNs have a high degree of component mixing. If we consider that the coexistence region between the two polymeric networks is the main cause of the inhomogeneities in the IPNs then it is obvious that a better structuring is observed for IPN-F2.

The aged films were investigated from the point of view of the mechanical and dielectric properties.

Stress-strain curves presented in Figure $8 a, b$ and the data centralized in Table 4 show that the blank IPN-R has an intermediary strain value (484\%) as compared with blank samples Net $A$ and Net $B$, which have elongations of $772 \%$ and $262 \%$, respectively. It is presumed that the second network limits the extension of the first network. ${ }^{58}$ 

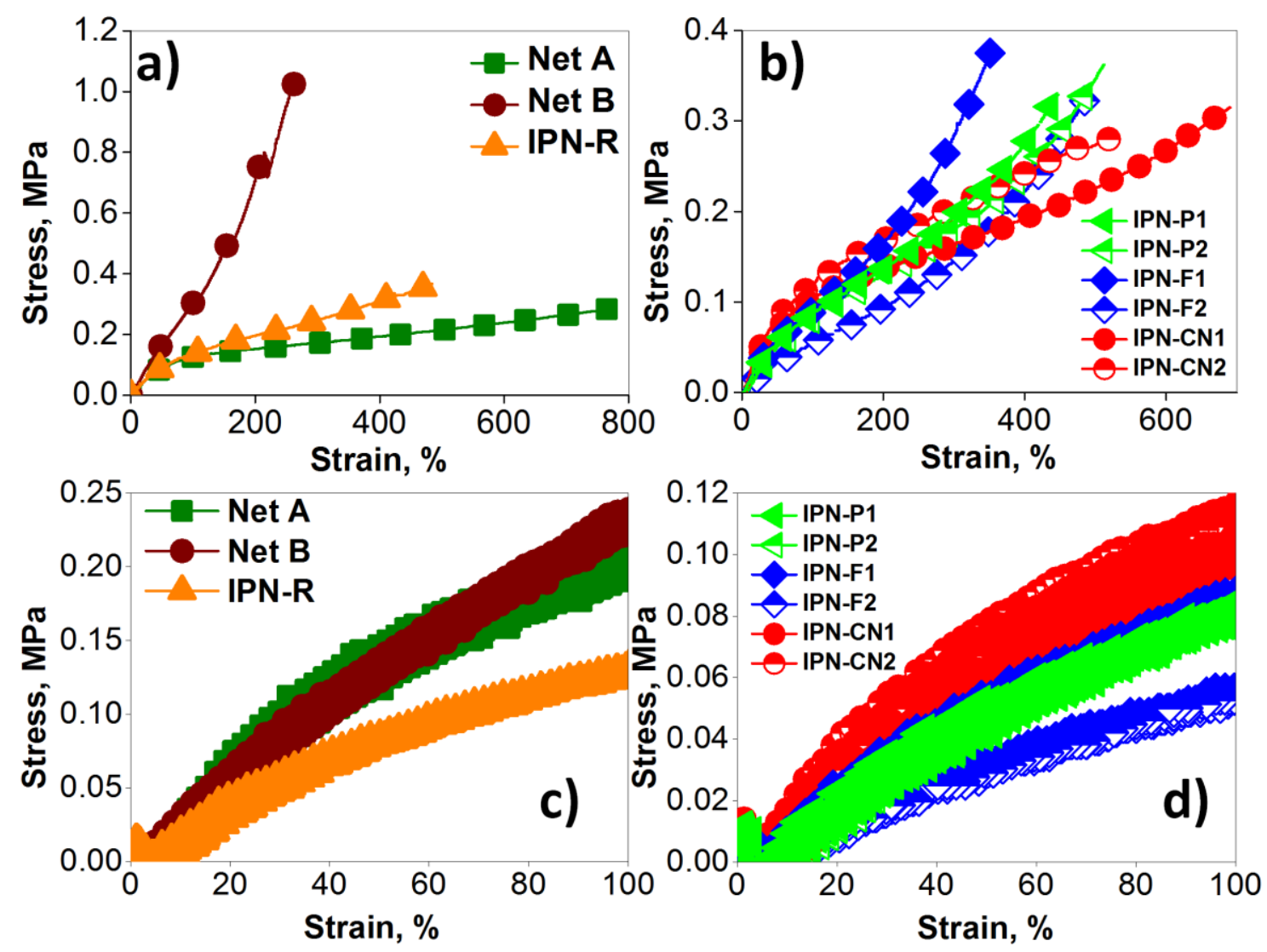

FIGURE 8 Mechanical test results: a - stress-strain curves for blank samples Net A, Net B, IPN-R; b - stress-strain curves for new IPNs; $c$ - cyclic stress-strain curves for blank samples Net A, Net B, IPN-R; d - cyclic stress-strain curves for the other IPNs.

By interpenetrating the networks containing phenyl or trifluoropropyl groups, a slight decreasing in elongation values as compared with IPN-R sample occurs. When the organic groups from the second networks are cyanpropyl randomized with hexyl ones, as in the samples IPN-CN1 and IPN-CN2, the elongation values are higher, 690 and $518 \%$, respectively. It is presumed that the long hexyl groups have lubrifiant effect allowing easy sliding of chains and networks to each other. Compared to our previously reported interconnected networks ${ }^{45}$ and to blends based on PDMS and cyanopropyl-modified silicones ${ }^{47}$, the mechanical properties of the IPN-CN samples have been seriously improved. This is on the one hand a positive effect of the IPNs preparation method, and on the other hand, an indirect proof for the formation of interpenetrating networks within the present reaction conditions. 
TABLE 4 The main mechanical and dielectric characteristics of the prepared IPNs measured at room temperature.

\begin{tabular}{lcccccccc}
\hline $\begin{array}{l}\text { Sample } \\
\text { Name }\end{array}$ & $\begin{array}{c}\text { Elastic } \\
\text { modulus, } \\
{\left[\mathrm{MPa}^{\mathrm{a})}\right]}\end{array}$ & $\begin{array}{c}\text { Young } \\
\text { modulus, } \\
{\left[\mathrm{MPa}^{\mathrm{b})}\right]}\end{array}$ & $\begin{array}{c}\text { Elongation, } \\
\varepsilon,[\%]\end{array}$ & $\begin{array}{c}\varepsilon^{\prime} \text { at } \\
5 \mathrm{~Hz}\end{array}$ & $\begin{array}{c}\varepsilon^{\prime} \text { at } \\
10^{4} \mathrm{~Hz}\end{array}$ & $\begin{array}{c}\varepsilon^{\prime \prime} \text { at } \\
5 \mathrm{~Hz}\end{array}$ & $\begin{array}{c}\varepsilon^{\prime \prime} \text { at } \\
10^{4} \mathrm{~Hz}\end{array}$ & $\begin{array}{c}\text { Breakdown } \\
\text { strength, } \\
{[\mathrm{MV} / \mathrm{m}]}\end{array}$ \\
\hline Net A & 1.77 & 0.20 & 770 & 2.97 & 2.95 & 0.32 & 0.0009 & $>60$ \\
Net B & 2.32 & 0.34 & 262 & 3.13 & 3.06 & 0.24 & 0.0050 & $>60$ \\
IPN-R & 1.72 & 0.27 & 484 & 2.96 & 2.92 & 0.56 & 0.0049 & $>60$ \\
IPN-P1 & 0.78 & 0.11 & 512 & 3.07 & 3.01 & 0.79 & 0.0041 & 12 \\
IPN-P2 & 0.69 & 0.10 & 447 & 3.09 & 2.97 & 1.70 & 0.0007 & 18 \\
IPN-F1 & 0.89 & 0.11 & 352 & 8.11 & 3.70 & 43.12 & 0.09714 & 16 \\
IPN-F2 & 0.56 & 0.03 & 486 & 5.85 & 3.62 & 68.49 & 0.1073 & 15 \\
IPN- & 0.94 & 0.13 & 690 & 9.27 & 2.96 & 10.75 & 0.0207 & 29 \\
CN1 & 1.25 & 0.20 & 518 & 3.95 & 3.46 & 0.98 & 0.0777 & 19 \\
IPN- & & & & & & & & \\
CN2 & & & & & & & & \\
\hline
\end{tabular}

${ }^{a}$ Young's modulus at upper limit of the elastic region; ${ }^{\mathrm{b}}$ Young's modulus at $10 \%$ strain

By analysing the data from Table 4, it can be seen that significant decreasing occur in Young modulus values when one of the networks contains polar groups attached. This tendency is more relevant for the samples IPN-Ps and IPN-Fs containing phenyl and trifluoropropyl groups. The cyclic stress-strain curves (Figure $8 \mathrm{c}, \mathrm{d}$ ) reveal very small hysteresis loops indicating low plastic deformations, this behaviour recommending the IPNs for applications where the samples are subjected to repeated mechanical stress. The value of the applied force appropriate to maximum elongation for each stress-strain cycle, according with the elongation rate, were calculated and plotted in Figure 9. It can be observed that only small changes appear in the stress relaxation from one cycle to another which demonstrates that the samples show a very small degree of relaxation. The region of elastic behaviour for each of prepared materials was estimated as elastic modulus values corresponding to upper limit of this region (Table 4) through the linearization of the first portion of stress-strain curves. Excepting IPN-CN1 and IPN-CN2 samples, which show elastic areas (17 and $16 \%$ strains, respectively) almost similar to those of reference networks. The other IPNs show a slight increase of the elasticity domain (19-21\%) compared to IPN-R (17\%). Also, it can be seen that the limit of elasticity of IPN-R is between the corresponding values of Net A (16\%) and Net B (18\%). These values are lower than those up to $40 \%$ found for RTV 615 from Bayer Silicones and Sylgard 184 from Dow Corning thermally treated $4 \mathrm{~h}$ at $200{ }^{\circ} \mathrm{C} .{ }^{59}$ 


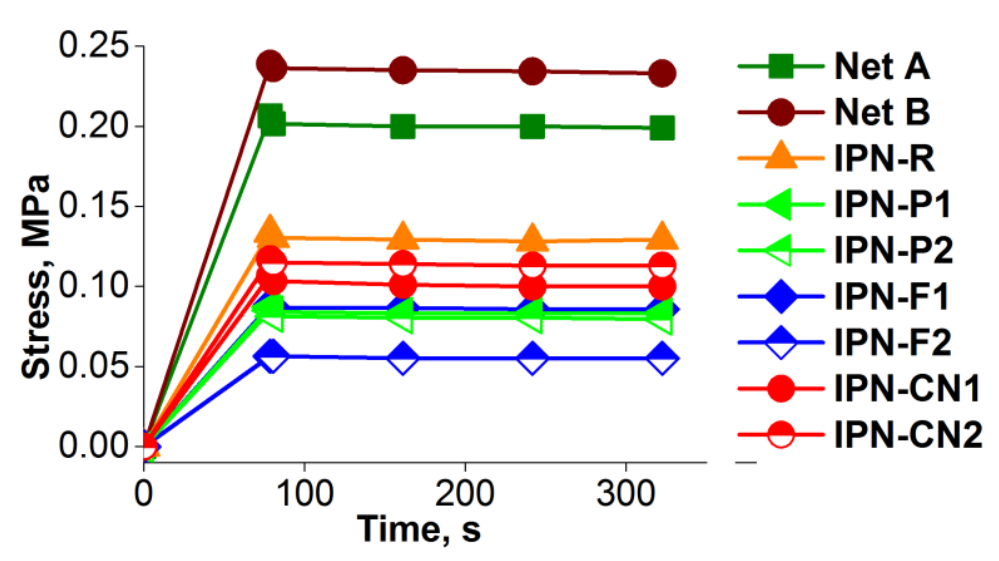

FIGURE 9 Stress relaxation for tested samples.

The permittivity and dielectric losses, as a function of frequency for IPN films containing different polar groups as compared with reference samples are plotted in Figure 10. By analysing the dielectric permittivity curves, it is clearly observed that although the blank samples have very close values for the dielectric permittivity $\left(2.92-3.06\right.$ at $\left.10^{4} \mathrm{~Hz}\right)$, a distinction between them can be done (Figure 10a). Thus, the Net B shows the greatest values of the dielectric permittivity throughout the frequency range. This could be due to crosslinking ladder pattern that reduces the free volume of the network. Net $A$ is crosslinked through chain ends and the sequences between crosslinks are longer thus having a lighter packing and this could leads to lower values of the dielectric permittivity. For IPNs, they decrease from the value corresponding to Net $B$ at $1 \mathrm{~Hz}$ to values lower even than those of the Net $A$ at frequencies above $10 \mathrm{~Hz}$ and decrease continuously within the studied frequency range. On the other hand, the dielectric permittivity values of the blank samples are maintained almost constant for the entire range of frequency excepting IPN-R where a small increasing in the low frequency range was observed (Figure 10a). At the same time, it was found an increasing of the dielectric losses for all samples in the low frequency range (Figure 10c). When polar groups are attached to one of the networks, as can be observed in Figure $10 \mathrm{~b}$ and Table 4, dielectric permittivity at low frequencies is significantly higher than for blank IPN, depending on the polarity of the organic groups. The highest value at $5 \mathrm{~Hz}$ was recorded for sample IPN-CN1 $(\varepsilon=9.27)$ followed by IPN-F1 $(\varepsilon=8.11)$. As the frequency increases, the permittivity decreases significantly reaching a plateau around $10^{3} \mathrm{~Hz}$ in all cases, as observed in the case of precursors of the IPN-CNs. ${ }^{24}$ In high frequency region, the differences between the values of dielectric permittivity of the analysed samples are not so high, at $10^{4} \mathrm{~Hz}$ these ranging between 2.96 (IPN-CN1), 2.97 (IPN-P1) and 3.63, 3.70 (IPNFs). The dielectric losses at low frequencies are also high reaching values of $\varepsilon "=68.49$ and 
43.12 in the case of IPN-Fs at $5 \mathrm{~Hz}$. As frequency increases, a significant decrease of dielectric losses occurs tending to zero (Figure 10d, Table 4).
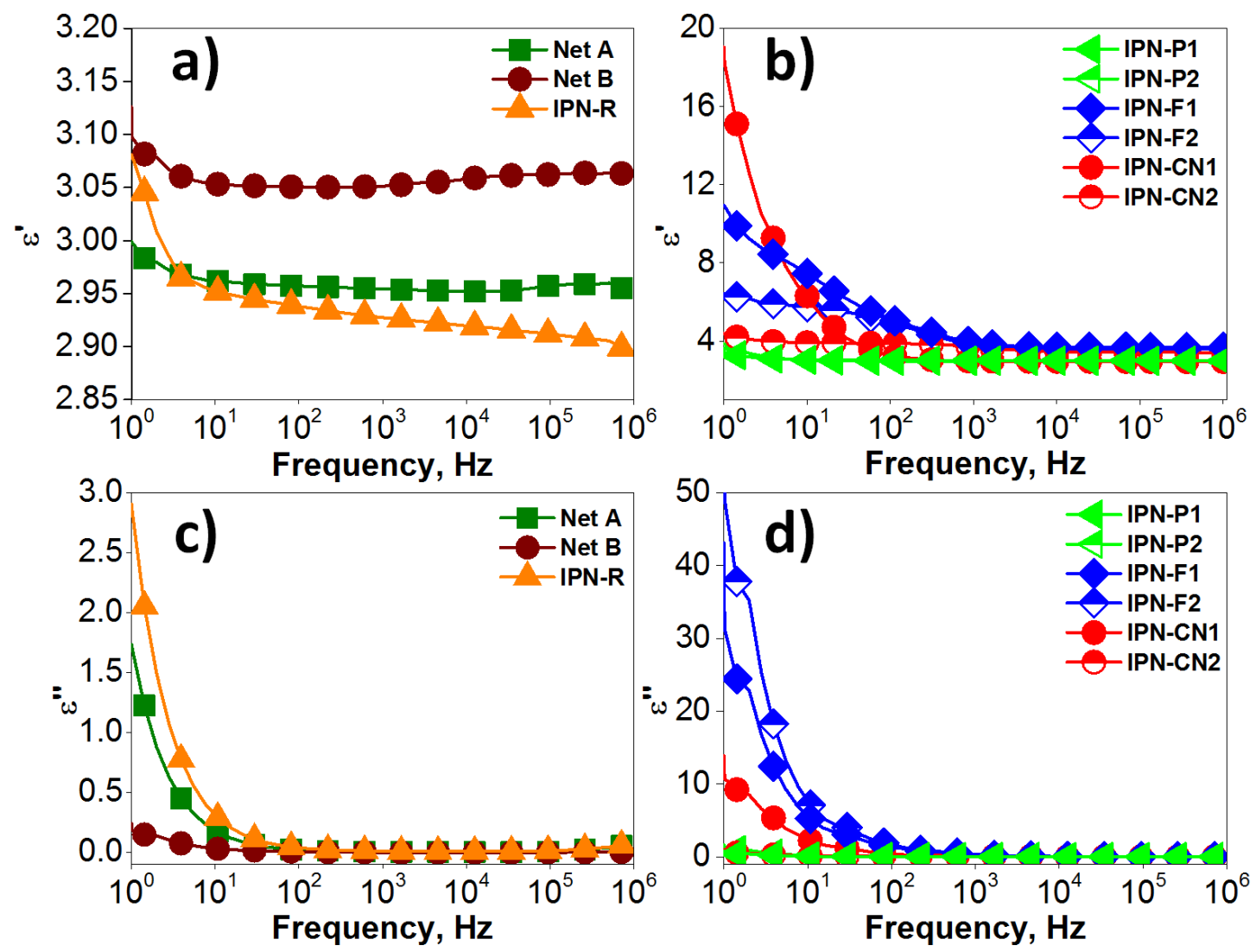

FIGURE 10 Dielectric spectra in dependence on frequency: a) dielectric permittivity of blank samples, Net A, Net B, IPN-R; b) dielectric permittivity of IPNs containing different percentages of polar groups, c) dielectric losses of blank samples and d) dielectric losses of IPNs containing different percentages of polar groups.

The breakdown field values reveal a clear decrease with the introduction of polar groups and their content, from > $60 \mathrm{MV} / \mathrm{m}$ in the cases of the reference samples Net A, Net B and IPN-R to $12-18 \mathrm{MV} / \mathrm{m}$ for IPN-Ps and IPN-Fs with a content of polar groups between 10.5 and 14.6 mole\%. Although they contain the most polar groups, the IPN-CNs show slightly higher breakdown field values (29 and $19 \mathrm{MV} / \mathrm{m}$ ) as compared with the previous because their content is very low ( 0.3 and 2.4 mole\%, respectively). The decreasing in breakdown field value as the polarity of the material increases is an expected, well-known behaviour due mainly to large dielectric losses. Failure to entirely dissipate heat generated by these losses, as well as increased amount of moisture absorbed that promotes electrolytic processes could be an explanation for this shortcoming. ${ }^{25}$ The values found for IPN-CNs are comparable with those reported by Risse et al. $^{47}$ for blends and much lower than those found for 
interconnected networks with cyanopropyl polar groups ${ }^{45}$. However, the measuring protocol in this case differs from the ones used by other groups ${ }^{47}$, i.e. we used a $400 \mathrm{~V} / \mathrm{s}$ ramp and 22 $\mathrm{mm}$ planar electrodes, versus 50 or $100 \mathrm{~V} / \mathrm{s}$ and spherical electrodes and the measurements were carried out in actuation mode, as it allowed our equipment. Thus, the film thickness when the breakdown occurs is lower than initial, at that the breakdown voltage was reported. While a larger electrode area and a greater ramp could give more accurate results in terms of overall material behaviour, the presence of small voids or other defects in the tested materials would clearly limit the breakdown values. Thus, the comparison with similar materials in the literature is rather imprecise.

The mechanical and dielectric characteristics can be used to estimate a parameter of interest for future potential application of such materials in electromechanical devices (e.g., actuation or harvesting). Thereby, the electromechanical sensitivity, $\beta$, was calculated using the dielectric permittivity $\left(\varepsilon^{\prime}\right)$ at $5 \mathrm{~Hz}$ and the Young's modulus $(Y)$ at $10 \%$ strain. ${ }^{60}$ Figure 11 reveals that the highest values, 74 and $195 \mathrm{MPa}^{-1}$, were obtained for IPN-F1 and IPN-F2 containing high percents (10.5 and 12.5 mol\%, respectively) of highly polar trifluoropropyl groups. This means an increase in this parameter with 573 and $1673 \%$, respectively, compared to the reference sample IPN-R (Figure 11b). These samples showed also the lowest values for Young modulus and highest values for dielectric permittivity (8.11 and 5.85, respectively) at $5 \mathrm{~Hz}$.
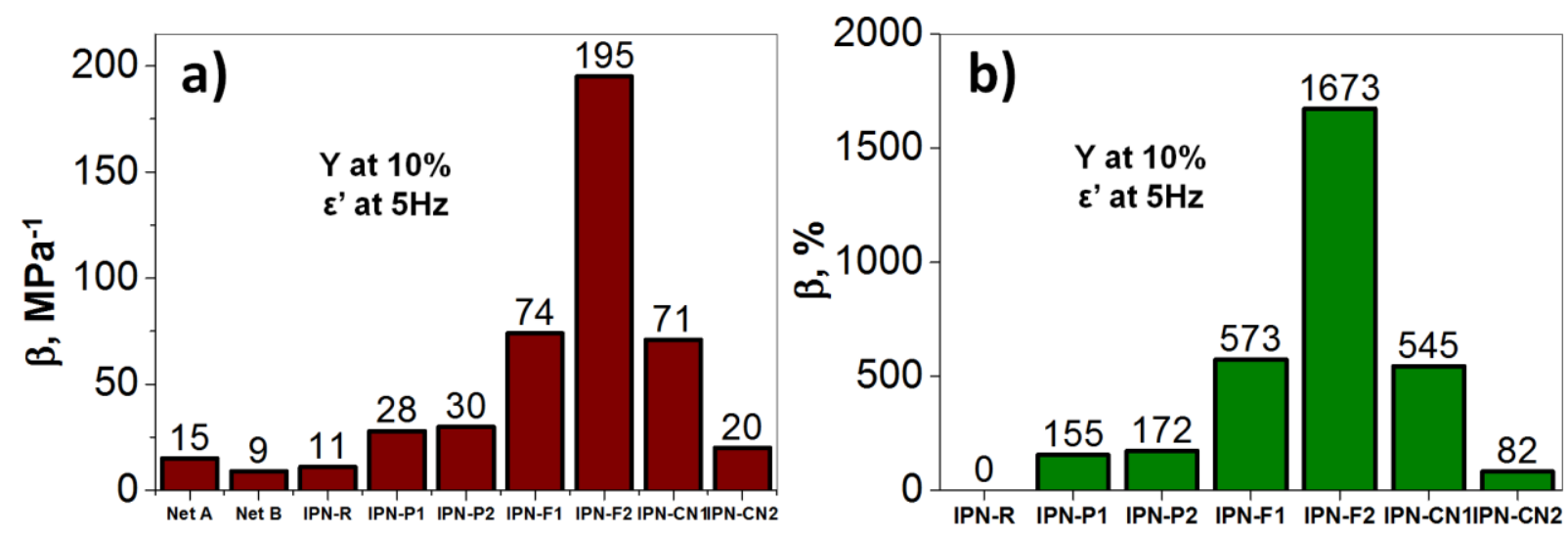

FIGURE 11 Comparative graphical representations of electromechanical sensitivity values: a) - absolute values calculated according to ref. ${ }^{57}$; b) - percentage changes in the electromechanical sensitivity of the IPNs as compared with reference IPN-R. 


\section{CONCLUSIONS}

Interpenetrating polymer networks (IPN) have been achieved based on two silicone systems, one of them containing various percents of trifluoropropyl, phenyl or 3-cyanopropyl groups along the chain. One silicone network consists in $\mathrm{OH}$-terminated siloxane copolymers cured by condensation, while the second one is composed by a $a, \omega$ bis(trimethylsiloxy)poly(dimethylmethyl-H-siloxane) or $\alpha, \omega$ bis(trimethylsiloxy)poly(methylcyanopropyl-methylhexyl-methylhydro)siloxanes crosslinked by addition with $\alpha, \omega$-bis(vinyl)-polydimethylsiloxane. Samples containing siloxane components with polar groups, even in low contents showed phase separation as SEM images and DSC curves revealed. SAXS results confirmed the IPNs structure by the presence of a degree of correlation between two domains as a function of distance of their separation. From mechanical point of view the IPN-CN1 sample showed the best strain (about $700 \%$ ) as compared with the blank IPN-R. In the same time, all samples have a small mechanical hysteresis when they are subjected to repeated cyclical stress tests. The dielectric results point out that the dielectric permittivity shows a significant increase only in the low frequency range where the dielectric losses are also high as compared with the blank samples but decreasing as frequency increases. At higher frequencies, the effect of the polar groups on the dielectric permittivity is less spectacular. However, the calculated electromechanical sensitivity point towards very promising actuation behaviour for the most polar networks, especially for the ones containing trifluoropropyl or cyanopropyl groups.

\section{ACKNOWLEDGEMENTS}

The work presented in this paper is developed in the context of the project PolyWEC (www.polywec.org, prj. ref. 309139), a FET-Energy project that is partially funded by the $7^{\text {th }}$ Framework Programme of European Community and co-financed by Romanian National Authority for Scientific Research, CNCS-UEFISCDI (Contract 205EU). We also acknowledge the support of Swiss National Science Foundation and UEFISCDI, under the SwissRomanian Research Program, grant No. IZERZO_142215/1(10 / RO-CH/RSRP/01.01.2013). Thanks to Dr. Stelian Vlad for mechanical measurements as well as to Dr. Cristian Varganici for DSC measurements.

\section{REFERENCES}

1. R. Pelrine, R. Kornbluh, J. Joseph, R. Heydt, Q. Pei, S. Chiba, Mater. Sci. Eng. C 2000, 11, 89.

2 C. Jean-Mistral, S. Basrour, J.-J. Chaillout, Smart Mater. Struct. 2010, 19, 085012. 
3 H. Oberhammer, J. E. Boggs, J. Am. Chem. Soc. 1980, 102, 7241.

4 D. Graiver and G. Fearon, In Silicon-Containing Polymers: The Science and Technology of Their Synthesis and Applications; G. Jones, Wataru Ando, J. C., Ed.; Kluwer Academic Publishers: Dordrecht, 2000; pp. 233-243.

5 J. A. Clarson, Stephen J.; Semlyen, Siloxane Polymers; Prentice Hall, 1993; p. 695.

$6 \quad$ P. H. V. and P. B. J C Lötters, W Olthuis, J. Micromechanics Microengineering 1997, 7,145

7 J. C. Lötters, W. Olthuis, P. H. Veltink, P. Bergveld, J. Micromechanics Microengineering 1997, 7, 145.

8 F. Vidal, C. Plesse, G. Palaprat, A. Kheddar, J. Citerin, D. Teyssié, C. Chevrot, Synth. Met. 2006, 156, 1299.

9 M. Liu, J. Sun, Q. Chen, Sensors Actuators A Phys. 2009, 151, 42.

10 A. Mata, A. J. Fleischman, S. Roy, Biomed. Microdevices 2005, 7, 281.

11 Y. Tanaka, K. Morishima, T. Shimizu, A. Kikuchi, M. Yamato, T. Okano, T. Kitamori, Lab Chip 2006, 6, 230.

12 J. Chon, S. Ye, K. J. Cha, S. C. Lee, Y. S. Koo, J. H. Jung, Y. K. Kwon, Chem. Mater. 2010, 22, 5445.

13 S. Nayak, T. Kumar Chaki, D. Khastgir, Adv. Mater. Res. 2013, 622-623, 897.

14 A. L. Skov, S. Vudayagiri, M. Benslimane, In SPIE Smart Structures and Materials + Nondestructive Evaluation and Health Monitoring; Bar-Cohen, Y., Ed.; International Society for Optics and Photonics, 2013; p. 86871I.

15 L. J. Romasanta, P. Leret, L. Casaban, M. Hernández, M. A. de la Rubia, J. F. Fernández, J. M. Kenny, M. A. Lopez-Manchado, R. Verdejo, J. Mater. Chem. 2012, 22, 24705.

16 H. Liu, L. Zhang, D. Yang, Y. Yu, L. Yao, M. Tian, Soft Mater. 2013, 11, 363.

17 J. Yang, M. Tian, Q.-X. Jia, J.-H. Shi, L.-Q. Zhang, S.-H. Lim, Z.-Z. Yu, Y.-W. Mai, Acta Mater. 2007, 55, 6372.

18 M. Cazacu, M. Ignat, C. Racles, M. Cristea, V. Musteata, D. Ovezea, D. Lipcinski, J. Compos. Mater. 2013, 48, 1533.

19 A. Bele, M. Cazacu, G. Stiubianu, S. Vlad, RSC Adv. 2014, 4, 58522.

20 A. Bele, M. Cazacu, G. Stiubianu, S. Vlad, M. Ignat, Compos. Part B Eng. 2015, 68, 237.

21 G. Gallone, F. Carpi, D. De Rossi, G. Levita, A. Marchetti, Mater. Sci. Eng. C 2007, 27, 110.

22 F. Carpi, G. Gallone, F. Galantini, D. De Rossi, Adv. Funct. Mater. 2008, 18, 235.

23 C. Racles, M. Cazacu, B. Fischer, D. M. Opris, Smart Mater. Struct. 2013, 22, 104004. 
24 C. Racles, M. Alexandru, A. Bele, V. E. Musteata, M. Cazacu, D. M. Opris, RSC Adv. 2014, 4, 37620.

25 Z. Ahmad, Dielectric Material; Silaghi, M. A., Ed.; InTech, 2012.

26 M. Misra, M. Agarwal, D. W. Sinkovits, S. K. Kumar, C. Wang, G. Pilania, R. Ramprasad, R. A. Weiss, X. Yuan, T. C. M. Chung, Macromolecules 2014, 47, 1122.

27 M. Niklaus, H. R. Shea, Acta Mater. 2011, 59, 830.

28 S. M. Ha, New Electroelastomers for High Performance Actuators; ProQuest, 2007; Vol. 0, p. 114.

29 Silicon-Containing Polymers: The Science and Technology of Their Synthesis and Applications; Springer Science \& Business Media, 2001; Vol. 30, p. 768.

30 B.-Y. Lim, S.-C. Kim, J. Memb. Sci. 2002, 209, 293.

31 L. H. Sterling, Encycl. Polym. Sci. Technol. 2004, 10, 272.

32 M.-S. Shin, S. J. Kim, I. Y. Kim, N. G. Kim, C. G. Song, S. I. Kim, J. Appl. Polym. Sci. 2002, 85, 957.

33 G.-S. Huang, Q. Li, L.-X. Jiang, J. Appl. Polym. Sci. 2002, 85, 545.

34 N. C. Goulbourne, Int. J. Solids Struct. 2011, 48, 1085.

35 S. M. Ha, W. Yuan, Q. Pei, R. Pelrine, S. Stanford, Adv. Mater. 2006, 18, 887.

36 S. M. Ha, W. Yuan, Q. Pei, R. Pelrine, S. Stanford, Smart Mater. Struct. 2007, 16, S280.

37 Soon Mok Ha; II Seok Park; Michael Wissler; Ron Pelrine; Scott Stanford; Kwang J. Kim; Gabor M. Kovacs; Qibing Pei, SPIE proceeding 2008, Proc. SPIE.

38 P. Brochu, H. Stoyanov, X. Niu, Q. Pei, Smart Mater. Struct. 2013, 22, 055022.

39 M. Cazacu, M. Marcu, J. Macromol. Sci. Part A 1995, 32, 1019.

40 M. Cazacu, A. Vlad, M. Alexandru, P. Budrugeac, C. Racles, F. lacomi, Polym. Bull. 2009, 64, 421.

41 M. Cazacu, M. Marcu, A. Vlad, D. Caraiman, C. Racles, Eur. Polym. J. 1999, 35, 1629.

42 Bruker AXS software.

43 C. Tugui, G Stiubianu, M lacob, C. Ursu, A. Bele, S. Vlad, M. Cazacu, J. Mater. Chem. C 2015, c, 8963

44 Chemistry Software, HyperChem, Molecular Modeling.

45 C. Racles, A. Bele, M. Dascalu, V. E. Musteata, C. D. Varganici, D. Ionita, S. Vlad, M. Cazacu, S.J. Dünki, D. M. Opris, RSC Adv. 2015, 5, 58428.

46 G. Stiubianu, M. Cazacu, A. Nicolescu, V. Hamciuc, S. Vlad, J. Polym. Res. 2010, 17, 837.

47 S. Risse, B. Kussmaul, H. Krüger, G. Kofod, Adv. Funct. Mater. 2012, 22, 3958.

48 Y. S. Lipatov, Phase-Separated Interpenetrating Polymer Network; 2006. 
49 S. C. Kim, D. Klempner, K. C. Frisch, H. L. Frisch, Macromolecules 1976, 9, 263.

50 Alex C. M. Kuo, Polymer Data Handbook 1999, 411.

51 J. H. An, A. M. Fernandez, L. H. Sperling, Macromolecules 1987, 20, 191.

52 S. Tan, D. Zhang, E. Zhou, Polym. Int. 1997, 42, 90.

53 X. Yu, G. Gao, J. Wang, F. Li, X. Tang, Polym. Int. 1999, 48, 805.

54 P. Debye, H. R. Anderson, H. Brumberger, J. Appl. Phys. 1957, 28, 679.

55 P. Debye, A. M. Bueche, J. Appl. Phys. 1949, 20, 518.

56 V. Nevissas, J. M. Widmaier, G. C. Meyer, J. Appl. Polym. Sci. 1988, 36, 1467.

57 D. J. Hourston, Y. Zia, J. Appl. Polym. Sci. 1984, 29, 629.

58 Z. Suo, J. Zhu, Appl. Phys. Lett. 2009, 95, 232909.

59 F. Schneider, T. Fellner, J. Wilde, U. Wallrabe, J. Micromech. Microeng. 2008, 18, 065008 (9pp)

60 H. Zhao, D.-R. Wang, J.-W. Zha, J. Zhao, Z.-M. Dang, J. Mater. Chem. A 2013, 1, 3140 . 
Graphical abstract (TOC):

Full silicone interpenetrating bi-networks with different organic groups attached to the silicon atoms

Codrin Tugui, Maria Cazacu, Liviu Sacarescu, Adrian Bele, George Stiubianu, Cristian Ursu, Carmen Racles

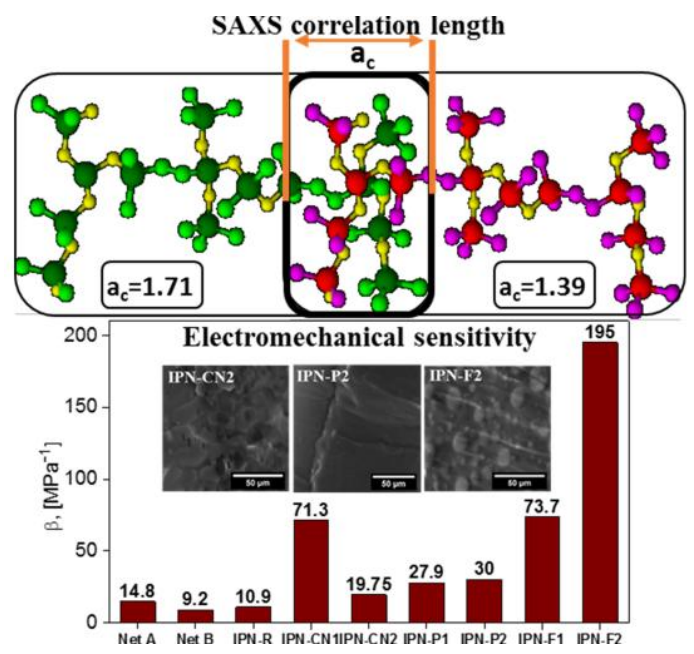


Click here to download Supplementary Material (online publication): Supporting information-r.docx Supplementary Material (online publication)
Click here to download Supplementary Mate

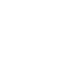

$\sqrt{3}$ (1)

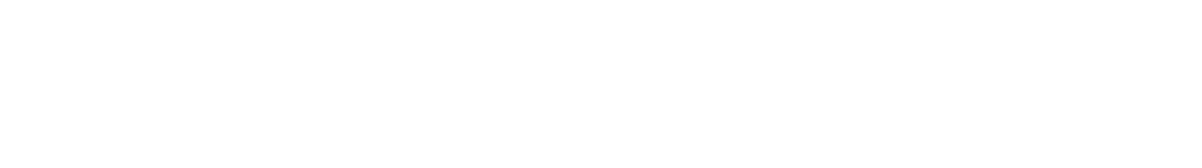

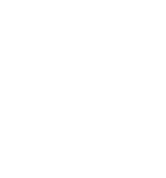
(1)

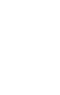
. (1) (1) $x^{2}$ .

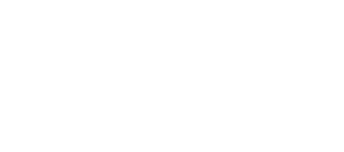
. .

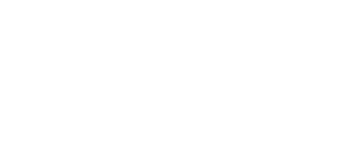

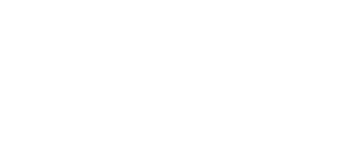

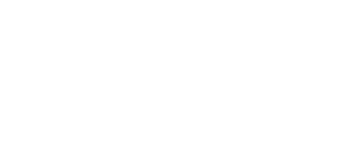

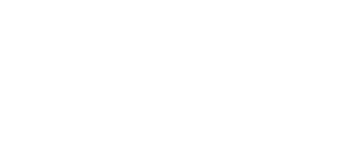

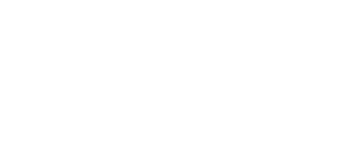

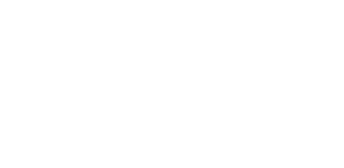

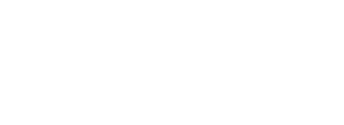




\section{Highlights}

-dielectric elastomers based on silicone interpenetrated networks (IPNs) were prepared

-polar groups were attached to one of the networks to raise the dielectric permittivity

•the constituent networks of the IPNs have been stabilized by sequential crosslinking

-the mixing degree of the two networks and morphology of the resulted IPNs were studied

•the measurements results show promising electromechanical behaviour for prepared IPNs 